\title{
The role of forensic pathology in suicide
}

\author{
Roger W. Byard • Amy Austin
}

Published online: 20 July 2010

(C) Springer Science+Business Media, LLC 2010

Suicide represents a significant category of preventable death in many countries and communities, and cases can occupy a considerable amount of time in forensic practice. In Australia, suicide was ranked as the fourteenth leading category of death in 2008, with 2,191 deaths [1]. In South Australia in 2009, there were 198 suicides out of 1,272 medicolegal autopsy cases that were performed at Forensic Science SA, the state forensic pathology facility, representing approximately $16 \%$ of the total case load.

Despite clear indications of deliberate self-destructive acts in many instances, it is however, sometimes difficult in specific cases to accurately designate the manner of death as suicide. For example, suicide notes are present in only a minority of cases, and may not necessarily have been written immediately preceding death. Cases where there has been a fall from a height exemplify these issues e.g. did a victim fall (an accident), was he or she pushed (a homicide), or did the victim jump (a suicide). Hanging deaths may also present difficulties in classification as this represents a very common method of suicide in many communities, but may also be responsible for death due to misadventure in cases of sexual asphyxia, or homicide if a drugged or otherwise incapacitated individual is deliberately suspended. Similar problems may occur with deaths due to drug toxicity, drowning, or in single occupant, single motor vehicle collisions. The pathological findings in these cases may be of no assistance in determining the intention of the deceased [2, 3].

Other cases where there may be difficulty in the assessment and classification include complex suicides

R. W. Byard $(\bowtie) \cdot$ A. Austin

Discipline of Anatomy and Pathology, The University of Adelaide, Frome Rd, Adelaide, SA 5000, Australia

e-mail: byard.roger@saugov.sa.gov.au where more than one lethal method has been used, or where the scene has been altered by relatives to disguise the true nature of the event, most often for religious or insurance purposes. It may also be difficult to differentiate certain suicide pacts from murder suicides [2].

Further problems occur in the overall assessment of suicides when national data are solely relied upon to interpret incidence and trends over time. Discrepancies in classifications in different jurisdictions, with added delays in finalizing cases, may mean that data capture varies from different areas, and that some deaths may be incorrectly assigned to later years. It has been suggested in Australia that a significant number of suicides have been classified as 'undetermined' manners of death, resulting in underreporting of suicide to the Australian Bureau of Statistics, the national data repository [4]. It has also been proposed that the apparent recent decline in suicide rates in Australia may be due to newly introduced changes in the Australian Bureau of Statistics data collection system [5]. Thus, not only may national data be suspect, but meaningful international comparisons may be compromised.

Where does forensic pathology stand in all of this? One strength that forensic institutions have is that despite often relatively low numbers of cases, there is a clear understanding of where the cases came from, why certain diagnoses have been arrived at, and how the data have been gathered. This means that studies from single institutions that service a specific geographical area may produce more reliable data than studies that have relied upon a larger body of information that has been compiled from subsets where different diagnostic and classification criteria have been used, and where capture of all cases may not be complete. Another disadvantage of national data is that local trends involving small numbers may be lost if data are pooled. 
An example of how local trends identified in forensic institutes may be useful in predicting national trends occurred in female suicides from hanging in South Australia from 1986 to 2000. The significant increase in these deaths that was reported in this study [6] was subsequently confirmed at the national level [7]. In a similar manner, the recent increase in suicides due to helium inhalation noted at Forensic Science SA, in South Australia, over the 25-year period from 1985 to 2009, was identified nationally when Australian data were examined [8].

Thus, individual forensic institutes have an excellent opportunity to identify significant trends that are occurring amongst suicide victims in their own jurisdictions [9], and this may have several advantages. Firstly, the conclusions derive directly from data that the investigators have contributed to, and so there should be a clear understanding of the limitations, and strengths of classifications and information capture. The confounding influences of different diagnostic and coding systems should also be minimised. Specific trends that are pertinent to the local community will be able to be identified more rapidly than if national data are relied upon, as formulation and publication of such information centrally may take several years to finalize. Finally, local trends may provide an early indication of similar trends occurring in large populations. Thus, smaller case series and analyses from single institutions may be extremely useful at both local and national levels. For this reason publication of such data should be encouraged, and the results included in national overviews and analyses of such deaths.

\section{References}

1. Australian Bureau of Statistics. 3303.0-Causes of death, Australia, 2008. [Online] 1994; [cited 20104 April]; Available from: URL:http://www.ausstats.abs.gov.au/Ausstats/subscriber.nsf/0/ E8510D1C8DC1AE1CCA2576F600139288/\$File/33030_2008.pdf.

2. Byard RW, Bramwell NH. Autoerotic death. A definition. Am J Forensic Med Pathol. 1991;12:74-6.

3. Perdekamp MG, Pollak S, Thierauf A. Medicolegal evaluation of suicidal deaths exemplified by the situation in Germany. Forensic Sci Med Pathol. 2010;6:58-70.

4. De Leo D, Dudley MJ, Aebersold CJ, et al. Achieving standardised reporting of suicide in Australia: rationale and program for change. Med J Aust. 2010;192:452-6.

5. Bradley CE, Harrison JE, Elnour AA. Appearances may deceive: what's going on with Australian suicide statistics? Med J Aust. 2010;192:428-9.

6. Large MM, Nielssen OB. Suicide in Australia: meta-analysis of rates and methods of suicide between 1988 and 2007. Med J Aust. 2010;192:432-7.

7. Byard RW, Klitte $\AA$, James RA, Gilbert JD. Changing patterns of female suicides: 1986-2000. J Clin Forensic Med. 2004;11:123-8.

8. Austin A, Winskog C, van den Heuvel C, Byard RW. Recent trends in suicides utilizing helium. J Forensic Sci (In press).

9. Vougiouklakis T, Tsiligianni T, Boumba VA. Children, adolescents and young adults suicide data from Epirus, northwestern Greece. Forensic Sci Med Pathol. 2009;5:269-73. 